\title{
Urban rail network connectivity in locating transfer stations: A case study of Tehran Urban Railway
}

\author{
Vahed Ghiasi ${ }^{1 *}$, Husaini Omar ${ }^{2}$, Zainuddin b. Md. Yusoff ${ }^{3}$, Samad Ghiasi ${ }^{4}$, Bujang.K.Huat ${ }^{5}$ \\ Ratnasamy Muniandy ${ }^{6}$, Moharam Baharvand ${ }^{7}$, Seyed Ghavamoddin Hosaini ${ }^{8}$,Morteza Souri ${ }^{9}$, \\ Nassimsadat Ghosni ${ }^{10}$, Amin Noushini ${ }^{11}$, \\ Mohammad Amin Afshar ${ }^{12}$, Arun Prasad ${ }^{13}$ and Sina Kazemian ${ }^{14}$ \\ ${ }^{1,2,3,5,6}$ Department of Civil Engineering, Faculty of Engineering, University Putra Malaysia 43400, Serdang, Selangor, \\ Malaysia. \\ ${ }^{1}$ Department of Civil Engineering, Faculty of Engineering, University of Malayer, Iran \\ 4, 7,8 Tehran Urban and Suburban Railway Company(TUSRC), Iran, \\ ${ }^{9}$ Islamic Azad University, Sciences and Research branch, Tehran, Iran \\ ${ }^{10,11}$ Faculty of Engineering, University Technology of Sidney, Australia \\ ${ }^{12}$ Faculty of Engineering, Iran University of Polytechnic (Amirkabir), Tehran, Iran \\ ${ }^{13}$ Department of Civil Engineering, Institute of Technology, Banaras Hindu University, Varanasi - 221005, India \\ ${ }^{14}$ Islamic Azad University, Boujnord Branch, Iran.
}

Accepted 11 November, 2010

\begin{abstract}
Public transport connectivity is defined as the ability to provide service to a maximum of trips through the optimal integration of lines, schedules, fare systems, information systems and modal transport facilities. Main interchange and big transfer stations are important factors in network connectivity. One of the objectives of this paper is defining the various types of interchange and transfer stations. Specifying the differences between these two is another aim of this paper. Finally, the process of locating interchange and transfer stations is discussed as the most important factor in network connectivity. Case study of Tehran urban rail network and the location of interchange and transfer stations is presented as an example of rail network connectivity.
\end{abstract}

Key words: Rail network connectivity, transfer station, interchanges station, public transport, Tehran, Iran.

\section{INTRODUCTION}

Connectivity can be defined as the existence of a connection or link between two points of network, which relates to the existence of direct or indirect links. The concept of inter-connectivity, however, varies from connectivity. Connectivity is a property of two nodes, while inter-connectivity is a property of at least three nodes of a link. The development of port depends on connectivity between the existing transport networks of the regions, which leads to good infrastructure facilities (Rietveld, 1997). Public transport connectivity is defined as the ability to provide service to a maximum of trips through the optimal integration of lines, schedules, fare

${ }^{*}$ Corresponding author. E-mail: Ghiasi_upm@yahoo.com. Tel: +60-17-2850-438. Fax: +603-89429150 systems, information systems and modal transport facilities. There is a double objective for optimizing the network connectivity:

First, is to promote a good support to the urban development by offering several options to the passengers in a specific urban area, especially the existing and planned urban centers and facilitate their trips. In that case, transport connectivity represents an anchorage of the public transport within the urbanization.

Second, is to facilitate the passenger transfers when required by well planned transport integration in order to increase especially the attractiveness of the urban rail but also more generally to increase the attractiveness of the public transport. In that case, transport connectivity integrates in the same place the different levels of services of the urban rail itself, but also when appropriate, the other public transport modes and the private 
Table 1. Urban rail interchange and transfer station definition.

\begin{tabular}{lll}
\hline Type & Urban rail - type of service \\
\hline Transfer station & 2 lines \\
Interchange & At least, 2 express lines or at least 3 lines \\
Transportation hub & $\begin{array}{l}\text { Interchange or transfer station + other modes: } \\
\text { Urban and intercity buses, rail, taxis, cars, etc. }\end{array}$
\end{tabular}

Table 2. General types of transfer stations.

Parallel lines Crossing lines

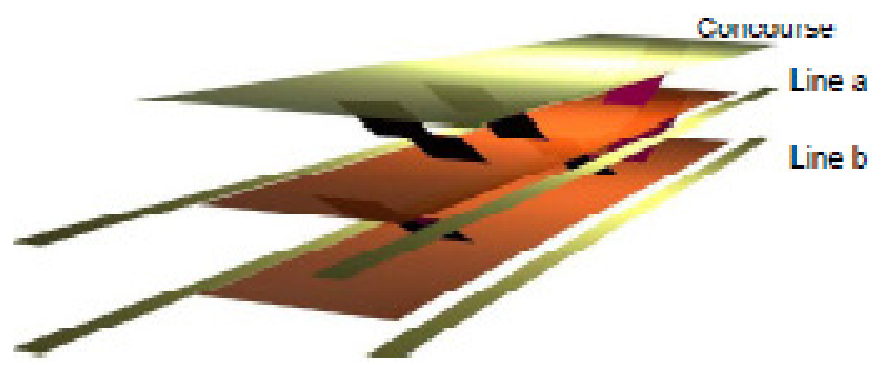

Figure 1. Both rail lines having central platforms.

modes.

There are two types of stations in rail network connectivity. Transfer stations which are the connection between two lines and main interchange stations that are the connection between at least three lines or two express lines (Spring, 2010). It should be stressed that main interchange stations as well as transfer stations require specific attention regarding the land-use surrounding the stations in order to facilitate the construction and the operation. In the following parts, some important issues about transfer stations are discussed as below:

1. Principles for the urban rail transfer and main interchange organization.

2. Characteristics for Tehran long term urban rail network main interchange stations.

The main result of this study is to achieve an optimized layout for allocation of main rail transit lines and specifying the connecting points. The scope of this study is limited to urban railway networks in large cities such as Tehran subway.

\section{PRINCIPLES FOR THE URBAN RAIL TRANSFER AND MAIN INTERCHANGE ORGANIZATION}

Here, the principle of organization of the transfer and main interchange stations to indicate possible typical functional organizations is given. Transfer stations are the connection between two lines and main interchange stations are the connection between at least three lines or two express lines. Urban rail interchange and transfer station definition is shown in Table 1.

\section{Transfer station principles}

Transfer stations are the connection between two lines. Depending on the lines passing through it, the transfer station can be either a connection between two lines running parallel at that section or two crossing lines. General types of transfer stations are illustrated in Table 2.

\section{Parallel rail line stations}

Depending on the transfer flows between the different directions of the lines connected, it would be interesting to use each of the following types of transfer stations. The distinction is mainly made related to the type of platform for each line: Central or lateral platform.

Both rail lines having central platforms: The two line platforms (Figure 1) can be planned to be superposed. This disposition is particularly convenient if both stations can be built at the same time and if the platforms have sufficient width. In this case, connections between the two lines would be rapid and convenient. The disadvantage of this option is that passengers entering the stations and wishing to access the lower level are obliged to pass through the upper before reaching their platform. This option is recommended when transfers rates between lines are much higher than boarding passengers. An example of this type of connection is the RER B and D in "Gare de Lyon" station in Paris.

The second option is having both platforms at the same 


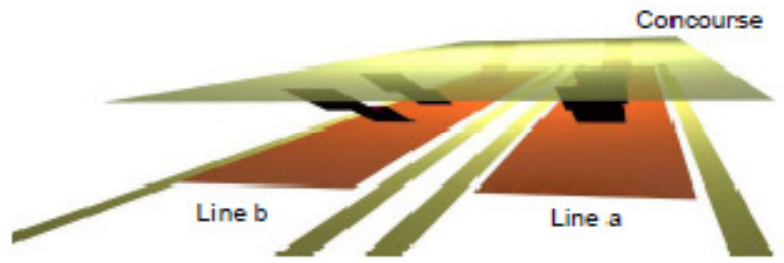

Figure 2. Both rail lines having central platforms.

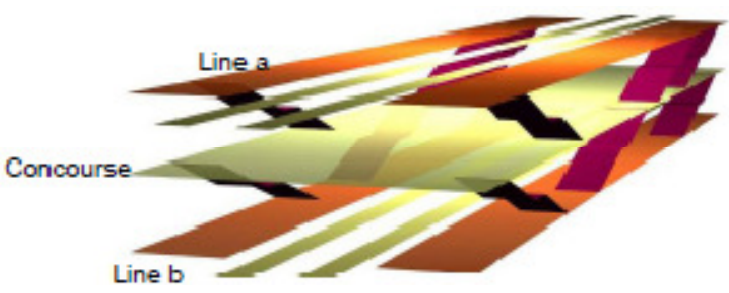

Figure 3. Rail lines having lateral platforms.

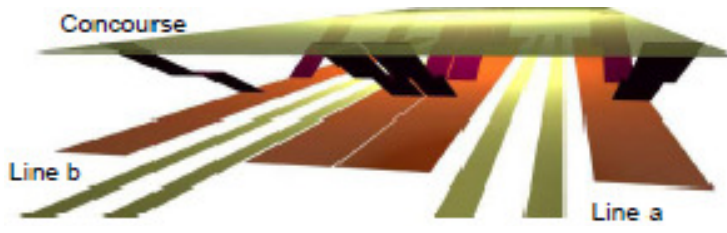

Figure 4. Rail lines having lateral platforms.

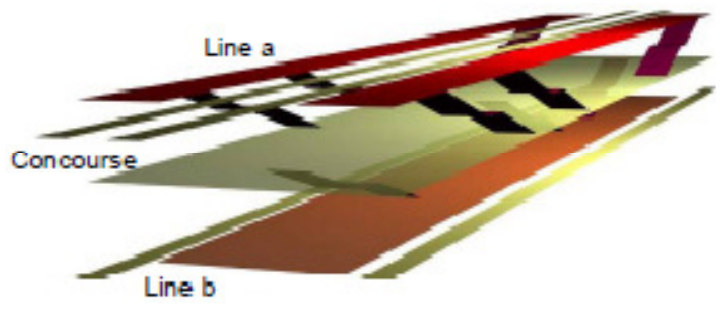

Figure 5. One rail line having a central platform, one rail line having a lateral platform.

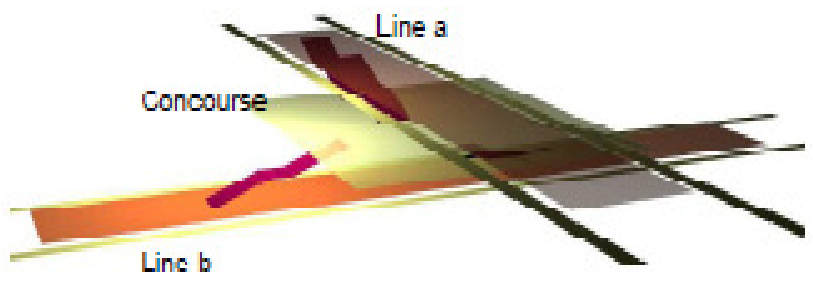

Figure 6. Both rail lines having central platform.

level and the concourse (including a transfer area) above (Figure 2). This is recommended when having similar flows of transfer and boarding passengers.

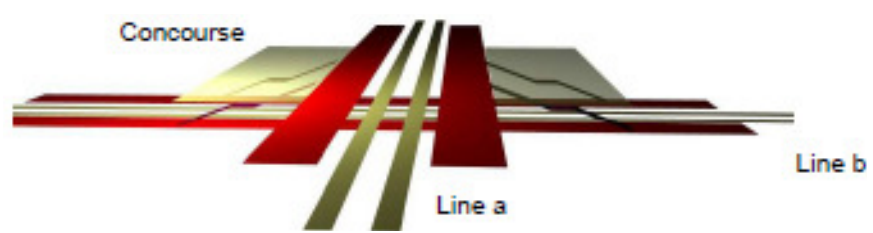

Figure 7. Both rail lines having lateral platforms.

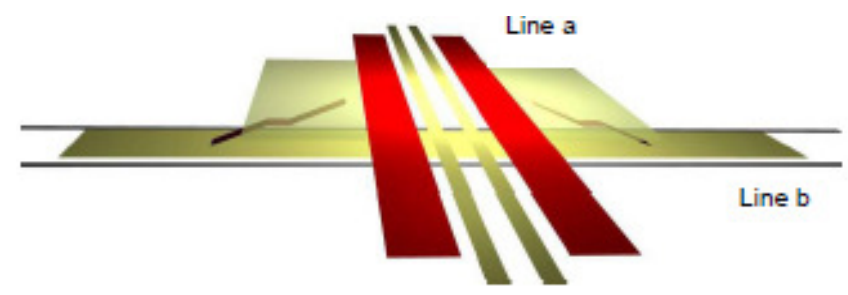

Figure 8. One rail lines having a central platform, one rail line having lateral platforms station

Rail lines having lateral platforms: In case of equivalent transfer flows between the different directions of the two lines (Figure 3), this option offers the opportunity to have a common transfer concourse located between both lines.

In case the transfer flows are dissymmetric, the two lines can be at the same level and the platforms can be located side by side. The other transfers will be made through a common concourse located above the platforms (Figure 4). This is the case in the connection of the RER A and B in "Chatelet-Les Halles" station in Paris. One rail line having a central platform, one rail line having a lateral platform: In this case, the two platforms must not be at the same level and a transfer concourse is required at the intermediate level between the platforms (Figure $5)$.

\section{Crossing rail stations}

Both rail lines having central platform: The connection between two crossing lines with central platforms (Figure 6) requires the implementation of an intermediate transfer concourse. Indeed, the intermediate concourse facilitates the implementation of stairs and especially escalators. The direct connection without any intermediate concourse is not recommended unless the station includes large platforms and light transfer flows.

Both rail lines having lateral platforms: This option (Figure 7) is more convenient than the previous one in terms of rapid connections between the platforms and easy transfer options. In addition, this option facilitates the implementation of escalators, between the different platforms.

One rail lines having a central platform, one rail line having lateral platforms station: This option (Figure 8) is 


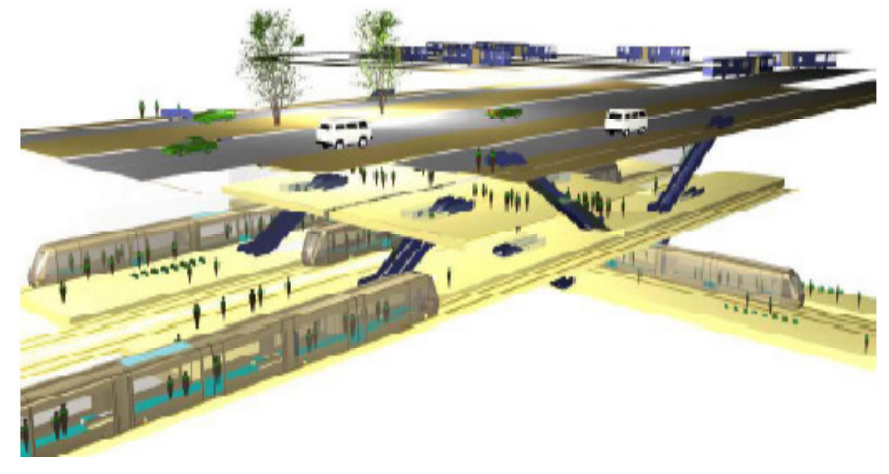

Figure 9. Sample of an interchange station.

also recommended as it offers direct transfer to all directions.

\section{Main interchange station principles}

Considering the complexity of the main interchange stations (Figure 9) and the importance of the adequacy between its functionality and its role, therefore the planning of the main interchange stations rarely follows the same principles and guidelines. Thus, it is recommended to study each main interchange station considering its specificities. It is also recommended to organize the platforms on 2 levels.

Optimizing the main interchange stations organization has a double benefit: A benefit on the construction costs, indeed by planning the main interchange stations during the feasibility studies of the lines, it is possible to make provisions for the future lines and avoid works on a constructed station, which can be very expensive. The economy can also come from the optimization of land use. A benefit on the transfer time and the accessibility, indeed to optimizing the main interchange stations aim at improving the transfer between the lines but also the access to the stations, and therefore the convenience of the station and the whole urban rail network.

\section{TEHRAN LONG TERM URBAN RAIL NETWORK CONNECTIVITY}

Greater Tehran in Iran is currently one of the most populated great cities in the world with an estimated present population of 14 million inhabitants. 12 million motorized trips are daily recorded and improving the public transportation conditions has become crucial in Tehran when the increasing road congestion jeopardizes air quality as well as economic profitability of the city workforce. In the near future, transportation has a critical role in supporting the development and reinforcing Tehran position as a high-ranked world city. The objective is to support the development of the existing and future urban centers with the help of main inter-change and big transfer stations. Considering the size, Tehran Urban Rail Network (TURN) which includes 54 transfer stations and 12 main interchange stations, specific attention should be paid to the organization of these stations. Indeed the passengers' transfer could be optimized, reducing the travel time and improving the journey conditions and comfort.

\section{Charecteristics of Tehran long term urban rail network transfer stations}

Tehran urban rail network includes 54 transfer stations. The aim of this paragraph is to identify Tehran urban rail network transfer stations and to characterize stations and lines organization (position) which is proposed at this level of study, the transfer stations can be divided into three types.

1. Connection between two committed urban lines $\left(\mathrm{n}^{\circ} 1\right.$ to $\left.n^{\circ} 4\right)$ or under study lines ( ${ }^{\circ} 6$ and $\left.n^{\circ} 7\right)$ : In this case, the studies concerning the station should have been carried out, and provisions for the connection must have been already made.

2. Connection between two new lines: In this case, the connection detailed study must be carried out during the feasibility and detailed studies of the first line to be implemented.

3. Connection between one new line and one line committed or under study: This final case is the most important and the more urgent to consider.

Indeed, in the case of connection between an existing line ( $n^{\circ} 1$ and $\left.n^{\circ} 2\right)$ and a new one, the connection with an existing station will have to be built; one of the lines already under operation. The construction could imply perturbations of the daily operation of the existing line. In case of a connection with an under construction or under study line (lines $n^{\circ} 3, n^{\circ} 4, n^{\circ} 6$ and $n^{\circ} 7$ ), the feasibility and detailed studies must take into consideration the connections with the future lines, in order to provide provisions for the future transfer stations. Line $\mathrm{n}{ }^{\circ}$ study seems to have already considered the connections with other new lines. It is recommended for the studies and construction for lines $n^{\circ} 3, n^{\circ} 4$ and $n^{\circ} 6$ to consider the future planned transfer stations. These stations are represented in yellow in the network Figure 10.

\section{Key characteristics of the main interchange station}

Site visits have been organized in order to collect urban information for each one. However, the detailed organization of the main interchange stations is out of scope of the paper and requires more specific studies; so the aim of this paragraph is to highlight the needs of organization and to provide preliminary concepts which should be 


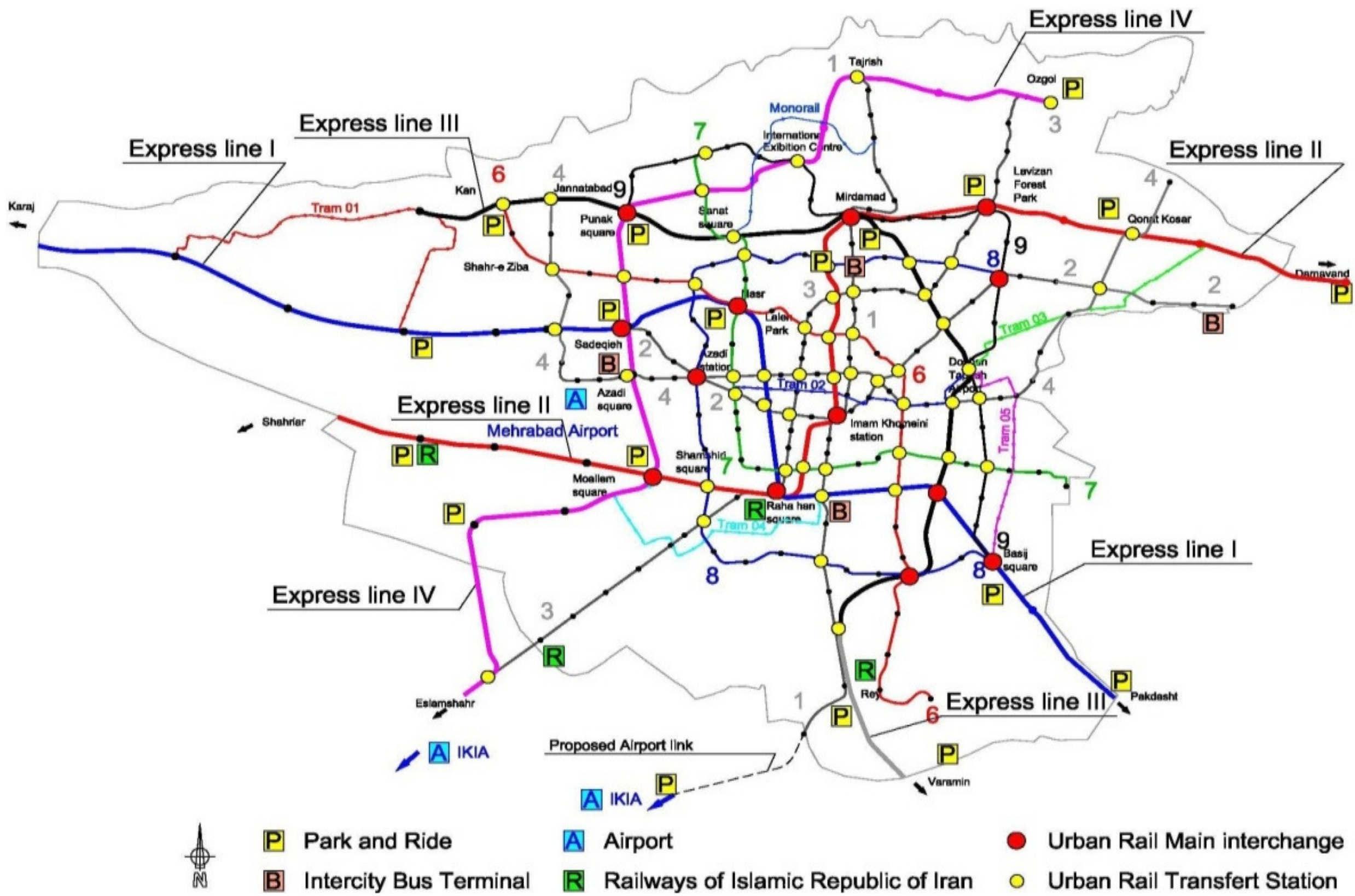

Figure 10. Tehran urban rail network - transfer and main interchange stations. 


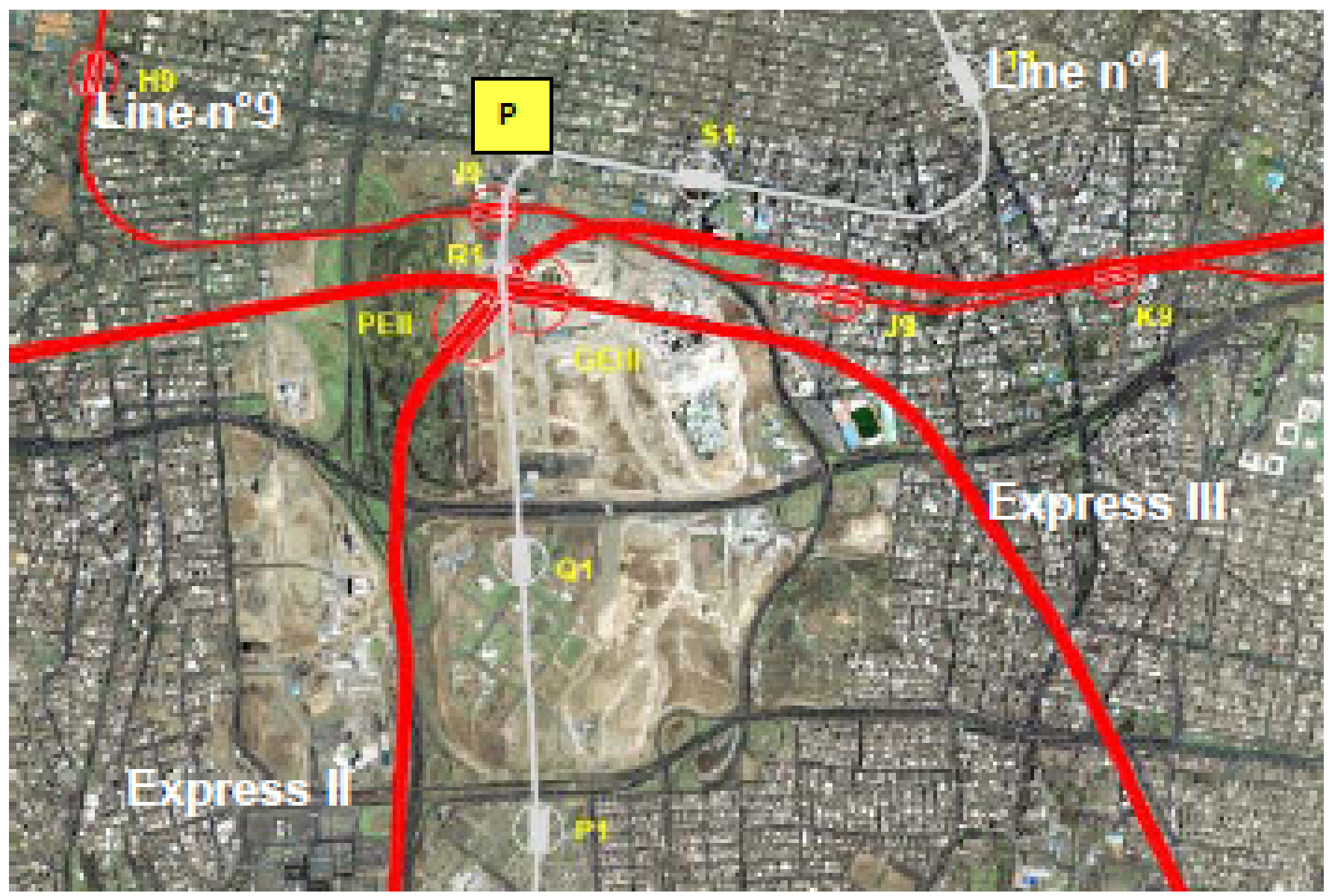

Figure 11. Haghani station.

analyzed more in-depth during next steps of more detailed studies.

Already, one of the major transport hubs in Tehran, Haghani (Figure 11) is for the time being the terminal station of line $n^{\circ 1}$ that collects all the passengers of the feeding buses of the north of Tehran. In the future, this station will be one of the major stations of Tehran with 4 lines that connect 2 express lines (Express II and III) and 2 urban lines $\left(n^{\circ} 1\right.$ and $n^{\circ} 9$ ). So, 3 new lines are planned to be implemented in addition to the existing urban line $\mathrm{n}{ }^{\circ}$. In addition a park and ride service is proposed to be implemented.

Express lines II and III could be implemented in the same area of the present R1 station, and the line $n^{\circ} 9$ would be located more into the north. The existence of line $n^{\circ} 9$ in the north could offer a possibility to have underground corridors be able to access from the other side of the expressway. At the present time, Haghani station has the advantage of relatively large space availability, which would facilitate the construction of future main interchange station. However, some projects are already planned for the area, considering its high attractiveness. It is highly recommended to consider the planned lines in the development of the new projects. A specific architectural study should be launched for the organization of this main interchange station. Table 3 summarizes the proposed layout for the main interchange stations which was presented in Figure 10.

\section{Connectivity of Tehran urban rail network}

In order to conclude, we should say the importance of the main interchange and transfer stations in the whole organization of the network, the role they play in terms of connectivity of the network, but also with regards to the urban organization should be underlined. Table 4 shows the different possible connections offered between the lines. Almost all the lines are connected between each other. It shows the excellent connectivity of Tehran urban rail network with 13 main interchange and 54 transfer stations. Only lines $n^{\circ} 6$ and $n^{\circ} 9$ and Express IV and line $n^{\circ} 8$ are not connected; the lines being nearly parallel.

\section{Tehran Long Term Urban Network Integration with other}

In order to improve the level of service of Tehran long 
Table 3. Proposal for the layout of the main interchange stations.

\begin{tabular}{|c|c|c|c|}
\hline Station & Name - location & Lines & Station level $\left({ }^{*}\right)$ \\
\hline \multirow[t]{3}{*}{ MIS 1} & Haghani & Urban $n^{\circ} 1$ & $\mathrm{G}-1$ \\
\hline & & Urban n`9 - Express III & G-2 \\
\hline & & Express II & G-3 \\
\hline \multirow[t]{3}{*}{ MIS 2} & Punak square & Express IV & $\mathrm{G}+1$ \\
\hline & & Urban n`9 & G-1 \\
\hline & & Express III & G-2 \\
\hline \multirow[t]{2}{*}{ MIS 3} & Lavizan Forest park - Mellat sq. & Urban n³ - Express II & G-1 \\
\hline & & Urban $n^{\circ} 9$ & G-2 \\
\hline \multirow[t]{2}{*}{ MIS 4} & Nasr & Express I - Urban ${ }^{\circ} 6$ & G-1 \\
\hline & & Urban $n{ }^{\circ 7}$ & G-2 \\
\hline \multirow[t]{2}{*}{ MIS 5} & Resalat square & Urban n8 & $\mathrm{G}+1$ \\
\hline & & Urban $n^{\circ} 2$ - Urban $n^{\circ} 9$ & G-1 \\
\hline \multirow[t]{2}{*}{ MIS 6} & Sadeqiyeh station & Express 1- Urban $n^{\circ} 2$ & G \\
\hline & & Express IV & G-1 \\
\hline \multirow[t]{3}{*}{ MIS 7} & Azadi Station & Urban $n{ }^{\circ} 2$ & G-1 \\
\hline & & Urban $n^{\circ} 4$ & G-2 \\
\hline & & Urban n̊8 & G-3 \\
\hline \multirow[t]{3}{*}{ MIS 8} & Imam Khomeyni station & Urban $n^{\circ} 1$ & G-1 \\
\hline & & Urban n`2 & G-2 \\
\hline & & Express II & G-3 \\
\hline \multirow[t]{2}{*}{ MIS 9} & Rah Ahan Square & Urban n³ - Express II & G-1 \\
\hline & & Express I & G-2 \\
\hline \multirow[t]{2}{*}{ MIS 10} & Shamshiri square & Express II & $G$ \\
\hline & & Express IV & G-1 \\
\hline \multirow[t]{3}{*}{ MIS 11} & Azadegan Exp. & Urban $n ` 8$ & $\mathrm{G}+1$ \\
\hline & & Urban $n^{\circ} 6$ & G-1 \\
\hline & & Express III & G-2 \\
\hline \multirow[t]{2}{*}{ MIS 12} & Khavaran Ahang / Shargh Exp. & Express I & G-1 \\
\hline & & Express III & G-2 \\
\hline \multirow[t]{2}{*}{ MIS 13} & Basij square & Urban $n^{\circ} 8-$ Urban $n^{\circ} 9$ & $\mathrm{G}+1$ \\
\hline & & Express I & G-1 \\
\hline
\end{tabular}

$\left(^{\star}\right)$ G: Ground level

term urban rail network, it is highly recommended to improve the interactions it will have with all the different other modes of transport, both public and private modes. An excellent integration between all modes of transport will benefit both functioning and inhabitants. Indeed, the combination with the other modes (private cars, buses, taxis) will increase the attractiveness of the network by improving the accessibility to the stations and especially the transfer and main interchange stations.

Figure 10 presents Tehran urban rail network connectivity, which includes a proposal of Park and Ride (P\&R) facilities and major bus terminals in connection 
Table 4. Transfer and main interchange stations between the lines.

\begin{tabular}{|c|c|c|c|c|c|c|c|c|c|c|c|c|}
\hline & Express I & Express II & Express III & Express IV & Urban n 1 & Urban n 2 & Urban n 3 & Urban $n{ }^{\circ} 4$ & Urban $n^{\circ} 6$ & Urban $n$ & Urban $\mathbf{n}^{\circ} 8$ & 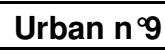 \\
\hline Express I & & MIS & MIS & MIS & TS & MIS - TS & MIS & 2 TS & MIS - TS & MIS & MIS & MIS \\
\hline Express II & MIS & & MIS & MIS & $2 \mathrm{MIS}$ & MIS & 2 MIS - TS & $2 \mathrm{TS}$ & TS & TS & $2 \mathrm{TS}$ & MIS \\
\hline Express III & MIS & MIS & & MIS & MIS - TS & TS & TS & $2 \mathrm{TS}$ & MIS - TS & $2 \mathrm{TS}$ & MIS - TS & 2 MIS - TS \\
\hline Express IV & MIS & MIS & MIS & & TS & MIS & TS & TS & TS & TS & - & MIS - TS \\
\hline Urban n¹ & TS & 2 MIS & MIS - TS & TS & & MIS & TS & TS & TS & TS & $2 \mathrm{TS}$ & MIS \\
\hline Urban $n^{\circ} 2$ & MIS - TS & MIS & TS & MIS & MIS & & TS & MIS - 2 TS & TS & TS & $2 \mathrm{MIS}$ & MIS \\
\hline Urban $n ³$ & MIS & 2 MIS - TS & TS & TS & TS & TS & & TS & TS & TS & $2 \mathrm{TS}$ & MIS \\
\hline Urban $n 4$ & 2 TS & 2 TS & 2 TS & TS & TS & MIS - 2 TS & TS & & $2 \mathrm{TS}$ & TS & MIS & TS \\
\hline Urban $n^{\circ} 6$ & MIS - TS & TS & MIS - TS & TS & TS & TS & TS & $2 \mathrm{TS}$ & & MIS - TS & MIS - TS & - \\
\hline Urban $n^{\circ} 7$ & MIS & TS & 2 TS & TS & TS & TS & TS & TS & MIS - TS & & TS & $2 \mathrm{TS}$ \\
\hline Urban n`8 & MIS & 2 TS & MIS - TS & - & $2 \mathrm{TS}$ & 2 MIS & $2 \mathrm{TS}$ & MIS & MIS - TS & TS & & $2 \mathrm{MIS}$ \\
\hline Urban $n ` 9$ & MIS & MIS & 2 MIS - TS & MIS - TS & MIS & MIS & MIS & TS & - & $2 \mathrm{TS}$ & 2 MIS & \\
\hline
\end{tabular}

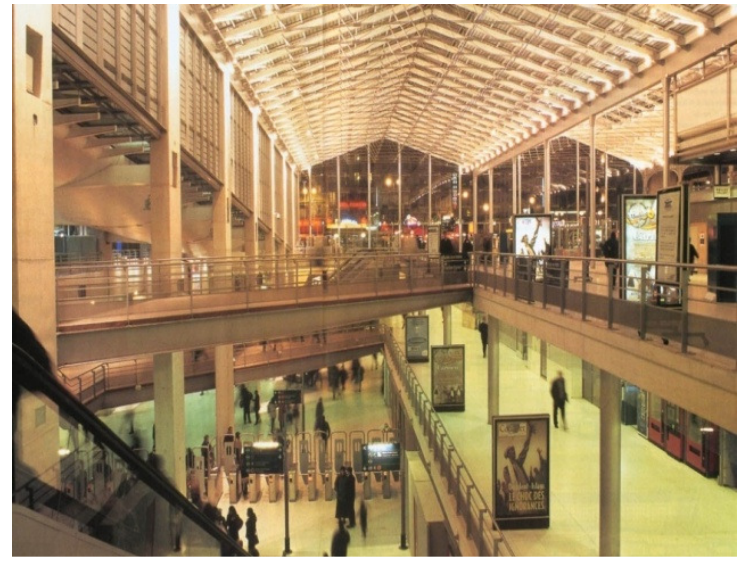

Figure 12. Gare du Nord interchanges station, Paris.

with the transfer and main interchange stations. The rapid increase of the car ownership and the important modal share of the private cars on the one hand and the traffic congestion on the other hand, imply that proposing Park and Ride systems on the main interchange stations will encourage the private mode users to transfer to the urban rai system. Indeed, it is reminded that the level of service planned to be supplied by Tehran urban rail network (Express and urban services) is excellent enough to compete with the private cars. This proposal will help the integration within the public modes but also between public and private modes, and therefore benefit to all the passengers, in terms of accessibility, comfort and journey time.

In addition, Figure 10 represents the integration between Tehran long term urban rail network and the national and international transport hubs. Figures 12 and 13 (Elsa, 2009) are taken in "Gare du Nord" station and Opera interchange station respectively in Paris; it shows the complexity of this station but also the numerous footbridges implemented to optimize the transfers within the station.

\section{CONCLUSION}

The internal organization of the station and the optimization of the passenger transfers between the lines are as important as the location of the station and its urban impact. Indeed, if the connections between the lines platform are carefully planned and well organized, it will facilitate the transfer at these stations and improve the attractiveness of the main interchange stations. Defining the various types of interchanges and transfer stations and specifying the differences between these are the objectives of this paper. The process of locating interchange and transfer stations is discussed as the most important factor in network connectivity. Tehran urban rail network and the location of interchange and transfer stations is presented as an example of rail network connectivity had discussed as a case study. In order to improve the level of service of Tehran long term urban rail network, it is highly recommended to improve the interaction; it will have with all the different other modes of transport, both public and private modes.

An excellent integration between all modes of transport will benefit to both functioning and to inhabitants. 


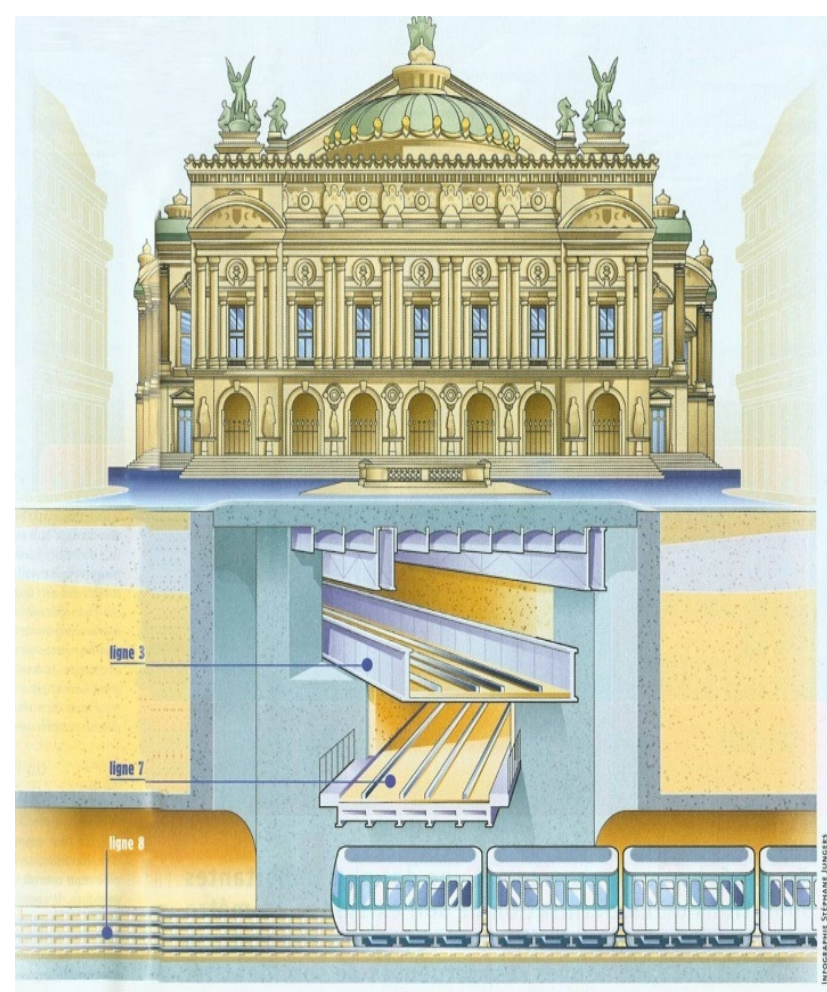

Figure 13. Example of Opera interchanges station, Paris.

\section{ACKNOWLEDGMENT}

Authors would like to acknowledge the Tehran Urban and Suburban Railway Company (TUSRC) for their support.

\section{REFERENCES}

Elsa V (2009). How underground culture is changing Paris. French Institute of Urban Planning, University Paris 8, Paris, France- Urban Research \& Practice., 2(1): 36-52.

Rietveld P (1997). Policy aspects of Interconnectivity in networks, in Cristina Capineri and Piet Rietveld (Eds), Networks in Transport and Communications - A Policy Approach (Ashgate Publishing Company: Vermont, USA), pp. 193-214.

Spring $\mathrm{CH}$ (2010). Determinants of passenger transfer waiting time at multi-modal connecting stations Original Research Article, Transportation Research Part E: Logist. Trans. Rev., 46(3): 404-413. 